\title{
THIN SECTION PREPARATION OF POPLAR TREE-RINGS FOR COMPUTER-AIDED IMAGE ANALYSIS IN DENDROCHRONOLOGICAL INVESTIGATIONS
}

\author{
Ruben F. Amparado, Jr., Hans Beeckman and Raoul Lemeur \\ Laboratory of Plant Ecology, State University of Ghent \\ Coupure links 653, B-9000 GENT, BELGIUM
}

\section{BUMMARY}

A methodology is outlined to measure histological poplar treering variables like vessel area, being sensitive ecological indicators.

Thin section preparation methods and a staining schedule are suggested to enhance contrast and to obtain best intensity colour for subsequent analyses of poplar treering variables, using a computeraided image analysis technique.

\section{INTRODUCTION}

Treering analysis holds much potential to study environmental impacts on trees and forests. A chronology of treerings is a natural time series, which, thanks to the yearly formed wood increment, provides information about the total life span of a tree.

Only recently have treerings been fully recognized as ecological sensors (Kairiukstis \& Cook, 1990) : treering analysis gives evidence to be a valuable tool in detecting environmental change. For example, treering measurements have been critically important in studies of forest decline in Europe and NorthAmerica. There are also attempts to use treering analysis for largescale ecological prognosis, including evaluation of carrying capacity of ecosystems. The wide range of application of modern dendrochronology beyond its traditional field and the complexity of treering datasets have placed heavy demands on methodological improvement, concerning as well variable selection, data collection as numerical analysis.

Contemporary dendrochronological studies require for instance histological examination of annual rings. Viewing the histological features of wood depends entirely on how well the prepared sample of that wood reveals its anatomical features.

\section{MATERIALS AND METHODS}

The area from which the samples were collected is located in an experimental field plot at Wachtebeke, northeast of Ghent, with geographical coordinates : latitude $51^{\circ} 09^{\prime} 25^{\prime \prime} \mathrm{N}$ and longitude $3^{\circ} 54^{\prime} 00^{\prime}$ ' E.

In spring 1974 a first part of the field was planted with two poplar clones : 'Unal' and 'Beaupré'. Populus $x$ euramericana (Dode) Guinier 'Beaupré' and 'Unal' are two of the famous fast growing hybrid clones of populus trichocarpa and Populus deltoides realized by extensive breeding work in 1961 by the State Equipment station for Poplar Culture, Geraardsbergen, Belgium (d'oultremont and Steenackers, 1973).

In spring 1990 fifteen 'BEAUPRE' trees from eleven different 
planting distances were felled down and disks five to seven centimeter thick were removed at approximately $1.3 \mathrm{~m}$ from the stem basis. The disks were marked in the field indicating the four quadrants where they were divided, one toward the north, the south and the other two at right angles to them. The quadrants were further subdivided into 1.5 to $2 \mathrm{~cm}$ cubes from which 60 micrometer thin transversal sections were removed using the sliding microtome of the heavy sledge type.

Thin section preparation

The following procedure is used :

i. a sharp well honed knife is prepared ;

ii. the cubes are clamped in the microtome;

iii. trimming cuts are made with the heel of the knife. The thickness gauge is set to 20 micrometer. In this case three sliding strokes are done before a final slice can be made.

iv. The knife is set between 15 to $20^{\circ}$ angle both vertically and to the line of travel. This is changed as necessary to prevent thick and thin cuts or excessive curling.

v. The cube is softened with a camel hair brush by brushing and wetting it with ethanol. This is repeated as often as may be necessary. The cube can now be readily sliced. The slide and cube are moved with steady firm movement across the knife. When the section should curl, it is turned upside down with the brush, uncurled and flattened. It is then wetted with ethanol and pushed to the upper portion of the blade for a few minutes. The procedure is continued by cutting other sections or transferring curled sections to a flat staining dish, flattening them and placing them curled side down in a flooded ethanol dish (see staining schedule). To prevent the curling of sections the angle of the blade can be changed.

\section{Staining schedule}

The sections are immersed in different concentrations of ethanol in flat staining dishes. The sections are transferred from one dish to another. In the process, air, water and extremely small pieces of wood that broke off during the cutting process, which can greatly affect the final resolution of the image, are removed.

i. immersion in $75 \%$ ethanol for 30 minutes;

ii. immersion in 90 \% ethanol for 30 minutes;

iii. immersion in $100 \%$ ethanol for 30 minutes ;

iv. the section is flooded in a safranin solution (1 gram safranin powder in $100 \mathrm{ml}$ distilled water) for 10 minutes ;

v. washing in $75 \%$ ethanol for 10 minutes ;

vi. washing in $90 \%$ ethanol for 10 minutes ; 
vii. washing in $100 \%$ ethanol for 10 minutes and drying for 5 minutes at the side of the dish before mounting. Steps $a$ and $e$ can be discarded and still obtain good results.

\section{Mounting on slides}

This is the most important part in the thin section preparation. Therefore care should be observed in order to produce excellent microscopic slides.

The following steps are suggested.

i. The slides and the cover glasses are cleaned ;

ii. Two to three drops of Euparal (mounting medium) are applied and spread. The thin section is fixed and the cover glass is affixed. One procedure is to place the medium on the edge of the cover glass and gently lower the tilted glass on to the sections forcing air bubbles out. Excess squeeze-out should be avoided to minimize cleanup problems. It is also for this reason that the thin section is predried.

iii. One or more lead weights may be placed on the cover slip to further flatten the wood sections and also to keep bubbles from forming while the slide is drying.

iv. To hasten the drying time the slides are placed in a drying oven or electric flat slide driers ; or open-air drying without heat.

v. The mounting medium that oozed out around the cover slip is removed with a scalpel or fingernail. If the medium is brittle, the excess is scraped away with a single-edged razor blade and slide and cover slip are wiped with a lint-free cloth or tissue paper dampened with alcohol.

vi. The slide is labelled appropriately.

\section{Image analysis}

In our on-going study, tree-ring variables like ring width (Beeckman, 1991), wood density and relative vessel area are studied. The annual vessel area is supposed to be a sensitive ecological indicator of the vitality of a tree (Sass and Eckstein, 1991).

Since the aim of the project is to evaluate the relation between the annual vessel area of poplar trees, meteorological variables and pollution effects, a large amount of data should be generated. Therefore, a computer-aided image analysis is essential.

Video-image-analysis systems were developed in the early 1960s. The early systems, based on mainframe computers, were used mostly by industry and medical research owing to limited availability and high cost (Jagels and Telewski, 1990). With the development of the minicomputer and the microcomputer, a wider range of applications has been reported.

Sells (1978), Micko et al. (1982), McMillan (1982), Telewski et al. (1983) and Sass and Eckstein (1991) have used video-image- analysis systems to determine the size and area of various tissues and cells and cell wall material in xylem. 
In our system a Leitz stereo microscope, a JVC CCD (Charged Coupled Device) three colour video camera and an Amstrad PC 1640 SD computer are essential units working in interrelation. The heart of the system is the video digitising and computer interface card. This accepts a 1 volt video signal, monochrome or colour, from a video camera.

The digitizer divides the image into a matrix of squares and rectangles, termed pixels. Each pixel has three coordinates : $X$ and $Y$ values that define the position of the pixel in the image and $a \mathrm{Z}$ value that represents the gray level or degree of brightness.

The picture from the camera, digitized into a grid of pixels, is displayed on the computer screen. The grid is 640 pixels horizontally by 350 vertically. The $z$ value, the intensity or threshold value, is a number between 0 and 255 . Black corresponds to zero and the brightest parts of the picture to 255. This

somewhat arbitrary scale of brightness can be adjusted up and down the "real world" range of light intensities. The best results will be found by brief experimentation.

The data used to produce the screen display is held in the screen memory of the computer, and from this memory data is taken for the various software discs to perform their measurement tasks on.

Basically they scan the memory for pixel data having intensity values greater than or less than certain threshold values set by the operator, and look at the numbers of such pixels, recognizing objects by groups of contiguous pixels, etc. Having objects pictured on a background that is very different in intensity to the objects is the ideal. Getting the threshold values right is the key to operating the system properly.

This allows the measurements of some tree-ring variables, like vessel area.

In order to attain high contrast which is essential in maximizing the use of the system, the thin section was stained with the red colour dye safranin. To attain high degree of precision and repeatability of measurements the following are set :

i. light intensity (microscope) : 6 ;

ii. magnification : $10 \mathrm{X}$;

iii. threshold intensity : 135, 255 ;

iv. colour contrast : red get ;

v. stage height from objective lens tip : $10 \mathrm{~cm}$.

vi. As a result, the light intensity of a fixed point on the screen having coordinates $(320,160)$ being the center, should be 161 .

A methodology in accordance with the procedure mentioned above gives the most reliable results in routine investigations of poplar tree-rings. That way subsequent inferences can be made based on time series analysis, canonical ordination of the data or even an structural learning method. 


\section{LITERATURE}

BEECKMAN, H. (1991). Redundancy analysis of tree rings and meteorological data in a Nelder design poplar plantation. Proc. Tree Rings and Environment. International Dendrochronological Symposium held at Ystad, South-Sweden. LUNDQUA Report, Lund 1991, in press.

COOK, E.R. \& KAIRIUKSTIS, L.A. (1990). Methods of dendrochronology. Applications in the Environmental Sciences. Kluwer Academic Publishers. Dordrecht Boston London. $394 \mathrm{p}$.

JAGELS, R. \& TELEWSKI, F.W. (1990). Computer-Aided Image Analysis of Tree Rings. In : COOK \& KAIRIUKSTIS (1990).

KAIRIUKSTIS, L.A. \& COOK, E.R. (1990). Preface. In : COOK \& KAIRIUKSTIS (1990)

MCMILLAN, C.W. (1982). Application of Automated Image Analysis to Wood Science. Wood Science 14: 97-105.

MICKO, M.M., A.D. YANCHUK, E.I.C. WANG \& TAYLOR, F.W. (1982) Computerized Measurement of Fiber Length. IAWA Bulletin N.S. 3 : 111-113.

d'OULTREMONT, Comte \& STEEENACKERS, V. (1972). A propos des nouvelles variétés de peupliers inscrites au contrôle variétal. Bull. Soc. Roy. For. de Belgique. 80,3 (110-135)

SASS, U. \& ECKSTEIN, D. (1991). The annual vessel area of beech as an ecological indicator. Proc. Tree Rings and Environment. International Dendrochronological symposium held at Ystad, South-Sweden. LUNDQUA Report, Lund 1991, in press.

SELLS, J. (1978). Quantitative automatische Bildanalyse in der aterialprüfung : Prinzip, Systemaufbau, Anwendung. Material und Technik $6: 79-83$.

TELEWSKI, F.W., WAKEFIELD, A.H. \& JAFFE, M.J. (1983). Computer-Assisted Image Analysis of Tissues of Ethrel-Treated Pinus taeda Seedlings. Plant Physiology 72 : 177-181. 
